\title{
Evaluation of the green supply chain management practices: A novel neutrosophic approach
}

\author{
M. Abdel-Baset ${ }^{\mathrm{a}, *}$, Victor Chang ${ }^{\mathrm{b}}$, Abduallah Gamal ${ }^{\mathrm{a}}$ \\ a Department of Decision Support, Faculty of Computers and Informatics, Zagazig University, Zagazig, Sharqiyah, Egypt \\ ' IBSS and RIBDA, Xi'an Jiaotong-Liverpool University, Suzhou, China
}

\section{A R T I C L E I N F O}

\section{Article history:}

Received 18 November 2018

Received in revised form 1 February 2019

Accepted 18 February 2019

Available online $\mathrm{xxx}$

\section{Keywords:}

Green supply chain management (GSCM)

Environmental performance

Neutrosophic set

Robust ranking

\begin{abstract}
A B S T R A C T
To attain competitive advantages and promote environmental performance, a proactive approach called green supply chain management (GSCM), has been extensively employed. In this paper, we use the robust ranking technique with neutrosophic set to handle practices and performances in GSCM. We evaluate GSCM practices using the robust ranking technique in order to detect practices leading to better economic and environmental performances. We employ the neutrosophic set theory to handle vague data, imprecise knowledge, incomplete information and linguistic imprecision. The efficiency of the proposed method is evaluated by using the first case study from petroleum industry in Egypt and the second case study from manufacturing firm in China. The results display that "reverse logistics", "supplier environmental collaboration", "carbon management" are the significant in GSCM practices. Both case studies verified that our proposal could be adopted for effectiveness and improvement. Our work could help managers and decision makers to become more environmentally responsible.
\end{abstract}

(c) 2019 Elsevier B.V. All rights reserved.

\section{Introduction}

In the past years, we witnessed an increased importance of the green supply chain management (SCM) operations of companies, conjugated to their general interest in environmental aspects. Legal environmental provisions, stakeholder pressures and globalization pushed enterprises and organizations to develop environmental practices and performances. Similarly, policies from the governments and increased public awareness may create demands for achieving better environmental management. Thus, organizations and enterprises are often obliged to improve their green image by performing environmental practices [1]. In recent years, the industry and academia have increased interests in GSCM [2], and particularly in integration of supply chain and natural environmental concerns in GSCM. This can be achieved by enforcing multiple green practices, like reverse logistics, green design, green purchasing, reuse, recycling and environmental technologies [3]. It is necessary to acquire a prospective competitive advantage and efficiency of GSCM by analyzing the interrelationships between the green practices and performances. There is a shortage of studies on GSCM practices and performances.

\footnotetext{
* Corresponding author.

E-mail addresses: m.basset.metwalli@outlook.com (M. Abdel-Baset), victorchang.research@gmail.com (V. Chang), abduallahgamal@gmail.com (A. Gamal).
}

The mutual relations between them should emphasize the need for further research. Rajeev et al. refer to the lack of studies linking GSCM practices, economic and environmental performances in [4]. Additionally, Rao et al. [5] determined a potential connection between green GSCM initiatives and improved economic performance.

Therefore, the aim of this research is to evaluate GSCM practices and performances, and to rank their importance using neutrosophic set with robust ranking technique approach.

The neutrosophic set is a generalization of the IFS considering the degrees of truthiness, falsity and indeterminacy. Actually, criteria are related and have a degree of intrusion relationships directly or indirectly. In this case, it is very complex for decision makers and experts to avert intrusion between criteria to gain a particular objective [6]. There are a few of methods qualified for handling mutuality between criteria.

The main achievements of this research are:

- Considering the significance of GSCM practices and performances and interdependent relations with an integrated neutrosophic set with robust ranking technique to achieve GSCM efficiency.

- Recognizing a comprehensive roster of GSCM practices and performances.

- The first case study of petroleum industry in Egypt is used to elect the best green practice, in order to improve environmental 
and economic performance. The second case study of a manufacturing firm in China is to validate our work can be adopted in a different context and measure the extent of improvements.

Neutrosophic numbers are employed in this research to explicit experts' preferences. The connotation of neutrosophic set was suggested by Smarandache [7] generalizing the concept of IFSs. The neutrosophic set is an extension of Atanassov intuitionistic fuzzy set, where the membership and non-membership of an element in a group is defined as a number between 0 and 1 . Neutrosophic set added another step further by examining the membership, the indeterminacy membership and the non-membership of an element of a given set as a number (0-1) [8]. Compared to Atanassov intuitionistic fuzzy set, the neutrosophic set is very effective in dealing with incomplete information and vague data. Hence, experts and decision makers use neutrosophic set to discern information in an uncertain environment [9]. The neutrosophic set received attentions from many researchers, developing, improving and expanding the neutrosophic theory [10-13]. Furthermore, it is a prerequisite to gain experts' opinions to estimate direct influences. However, crisp or deterministic numbers cannot illustrate the linguistic imprecision and ambiguity of experts' opinions. Consequently, to cope with this drawback, we use neutrosophic numbers [13]. The neutrosophic set introduces the indeterminacy degree, which helps experts to explicit their opinions more accurately [7].

In this research, the robust ranking technique, employed in many papers [14-17] for easier and faster ordering of results, is used to rank the information obtained from experts.

The paper is organized as follows: Section 2 passes in review the green supply literature. Section 3 illustrates the preliminaries of neutrosophic set. Section 4 explains the procedure solution. In Sections 5 and 6 , we describe two supporting case studies to demonstrate the practicality of the method, with results and analysis. In Section 7, we present discussion and finally, we conclude our research with summary of research contributions and future work.

\section{Literature review}

\subsection{Green supply chain management (GSCM)}

In the last decade, GSCM witnessed remarkable growth varying from practical development to empirical and theoretical researches [18-20]. Hervani characterized GSCM as a combination of green design, materials management, green purchasing, supplier environmental collaboration and reverse logistics to hinder the loop. Over the years, the definition of GSCM varied. Srivastava determined GSCM as a collection of environmental consequences into SCM, including green design, selection of materials, manufacturing and product end-of-life [21]. According to [21], GSCM can decrease the negative effects (air, water, and land pollution) and garbage of resources (energy, materials, and products) of industrial activity. Many researchers and students described scrupulous GSCM practices using real case studies for implementation [22-24]. Table 1 epitomizes recent definitions of GSCM practices.

\subsection{GSCM practices}

According to this paper, there are different green practices through which the green supply chain can be achieved [27].

\subsubsection{Reverse logistics}

There are many products with remaining value, but not used at the end of lifespan. Reverse logistics is the collection of products and materials used by customers and users for reuse, recycling, or other purposes. This process treats these materials as valuable industrial inputs rather than being disposed of in the form of waste [25]. The following figure shows the practice of reverse logistics (Fig. 1).

\subsubsection{Green purchasing}

Companies can supply design directives for suppliers through incorporating green principles into purchasing, which have environmental requirements for the green purchased materials. Green purchasing encompasses topics like serious material minimization, refuse reduction and environmental material substitution. Therefore, organizations have to ensure suppliers' environmental performance and environmentally friendly materials [28].

\subsubsection{Carbon management}

With rising environmental and climate variation worries in the green supply chain, companies admitted the carbon issue as one of the remarkable practice in GSCM [2]. Companies began utilizing the outcomes of carbon footprint to reduce energy consumption and manufacturing costs.

\subsection{Case studies as a research method}

Case studies have been used extensively in research. When theories have been developed and expanded into a list of guidelines, policies, examples and best practices, they can be developed into a structured method. One of such a method is

Table 1

The definition of GSCM practices.

\begin{tabular}{|c|c|}
\hline Expression, term & Definition \\
\hline Reverse logistics & $\begin{array}{l}\text { Reverse logistics is the collection of products and materials used by customers and users for reuse, recycling, or other purposes. This } \\
\text { process treats these materials as valuable industrial inputs rather than being disposed of in the form of waste. }\end{array}$ \\
\hline $\begin{array}{l}\text { Internal environmental } \\
\text { management }\end{array}$ & $\begin{array}{l}\text { Internal environmental management is the practice of evolving green supply chain management as a strategic organizational essential } \\
\text { through involvement and favor of the involuntary from senior and mid-level managers [25]. }\end{array}$ \\
\hline Green purchasing & Green purchasing converges on collaboration with suppliers for the aim to enhancing products that are environmentally sustainable [25]. \\
\hline Cooperation with customers & $\begin{array}{l}\text { Collaboration with customers requires working with customers to design cleaner production processes that produce environmentally } \\
\text { prospective products with green packaging [25]. }\end{array}$ \\
\hline Environmental performance & $\begin{array}{l}\text { Environmental performance relates the ability of manufacturing plants to decline air resurrections, effluent waste, and solid wastes, and } \\
\text { the ability to decrease consumption of hazardous and toxic materials [25]. }\end{array}$ \\
\hline Economic performance & $\begin{array}{l}\text { Economic performance relates to the manufacturing plant's capability to minimize costs related with purchased materials, energy } \\
\text { consuming, waste evacuation, waste discharge, and mulcts for environmental episodes [24]. }\end{array}$ \\
\hline Operational performance & $\begin{array}{l}\text { Operational performance connects to the manufacturing plant's capabilities to more efficiently produce and convey products to } \\
\text { customers [26]. }\end{array}$ \\
\hline Organizational performance & Organizational performance, financial and marketing performance of the organization as contrasted to the industry rate [26]. \\
\hline
\end{tabular}




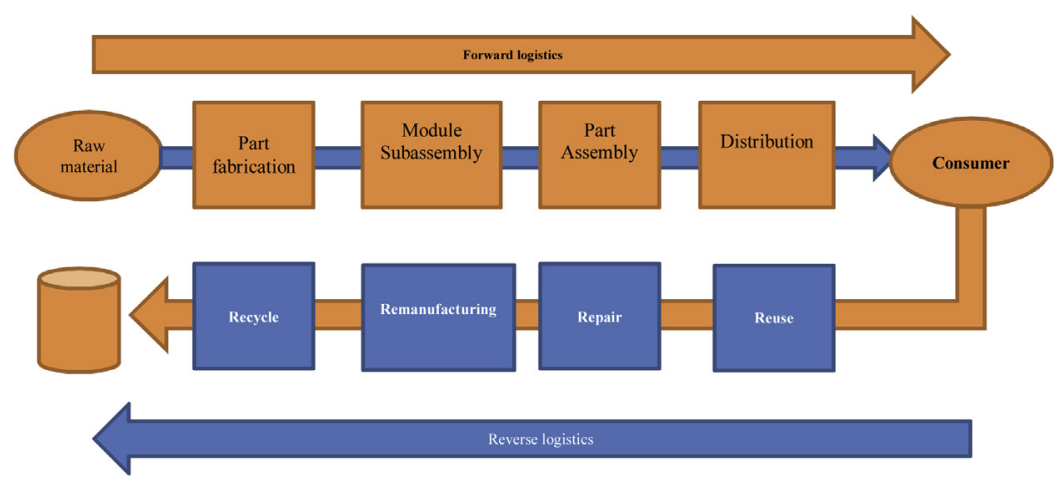

Fig. 1. The reverse logistics.

known as case studies [38,39]. They can represent how theories can be developed into lessons learned and real life examples. It is a common way to demonstrate how to blend theories and practices.

Case studies can be adopted and illustrated in our paper as follows. First, neutrosophic research is often focused on the theoretical development and its expansion on several models. The use of case studies can support its validity and theoretical contributions. Second, case studies can also represent how researchers can blend theories and practical solutions together. If the proposed solution can be demonstrated to address identified challenges, it can offer more meaningful research contributions.

The case studies are selected based on the development of the countries, suitability of the research agenda, existing needs in the area of research and the applicability for the potential real life contributions. For example, this research is relevant for the development countries, since they need to develop economy while maintaining an acceptable level of sustainability and green supply chain. Egypt was chosen since it is a better economy in Africa, and green supply chain has played a more important role. Similarly, China has become a strong merging economy. The use of green supply chain has become more important to maintain a good environment and reduce impacts caused by pollution and wastes. Netrosophic research can be effectively used and illustrated, so that the selection of green suppliers can be consistent, fair, transparent and easy to follow. These two case studies will be presented in Sections 5 and 6 respectively.

\section{Preliminaries}

In this section, we give the definitions of neutrosophic sets, single valued neutrosophic sets, trapezoidal neutrosophic numbers, and discuss about the operations on trapezoidal neutrosophic numbers.

Definition 1. .[17] Let $X$ be a space of points, $x \in X$. A neutrosophic set $A$ in $X$ is defined by a truth-membership function $T_{A}(x)$, an indeterminacy-membership function $I_{A}(x)$ and a falsity-membership function $F_{A}(x) . T_{A}(x), I_{A}(x)$ and $F_{A}(x)$ are real standard or real nonstandard subsets of $]-0,1+\left[\right.$. That is, $T_{A}(x)$ : $X \rightarrow]-0,1+\left[, I_{A}(x): X \rightarrow\right]-0,1+\left[\right.$ and $\left.F_{A}(x): X \rightarrow\right]-0,1+[$. There is no restriction on the sum of $T_{A}(x), I_{A}(x)$ and $F_{A}(x)$, so $0-\leq$ sup $(x)+\sup x+\sup x \leq 3+$.

Definition 2. [29-32] Let $X$ be a universe of discourse. A single valued neutrosophic set $A$ over $X$ is an object taking the form $A=\left\{\left\langle x, T_{A}(x), I_{A}(x), F_{A}(x),\right\rangle: x \in X\right\}$, where $T_{A}(x): X \rightarrow[0,1], I_{A}(x)$ : $X \rightarrow[0,1]$ and $F_{A}(x): X \rightarrow[0,1]$ with $0 \leq T_{A}(x)+I_{A}(x)+F_{A}(x) \leq 3$ for all $x \in X$. The intervals $T_{A}(x), I_{A}(x)$ and $F_{A}(x)$ represent the truthmembership degree, the indeterminacy-membership degree and the falsity membership degree of $x$ to $A$, respectively. For convenience, a SVN number is represented by $A=(a, b, c)$, where $a, b, c \in[0,1]$ and $a+b+c \leq 3$.

Definition 3. .[33,34] Suppose $\alpha_{\tilde{a}}, \theta_{\tilde{a}}, \beta_{\tilde{a}} \in[0,1]$ and $a_{1}, a_{2}, a_{3}$, $a_{4} \in \mathrm{R}$, where $a_{1} \leq a_{2} \leq a_{3} \leq a_{4}$. Then, a single valued trapezoidal neutrosophic number $\tilde{a}=\left\langle\left(a_{1}, a_{2}, a_{3}, a_{4}\right) ; \alpha_{\tilde{a}}, \theta_{\tilde{a}}, \beta_{\tilde{a}}\right\rangle$ is a special neutrosophic set on the real line set $R$, whose truth-membership, indeterminacy-membership and falsity-membership functions are defined as:

$$
T_{\tilde{a}}(x)=\left\{\begin{array}{cc}
\alpha_{\tilde{a}}\left(\frac{x-a_{1}}{a_{2}-a_{1}}\right) & \left(a_{1} \leq x \leq a_{2}\right) \\
\alpha_{\tilde{a}} & \left(a_{2} \leq x \leq a_{3}\right) \\
\alpha_{\tilde{a}}\left(\frac{a_{4}-x}{a_{4}-a_{3}}\right) & \left(a_{3} \leq x \leq a_{4}\right) \\
0 & \text { otherwise }
\end{array}\right.
$$

$I_{\tilde{a}}(x)=\left\{\begin{array}{cc}\frac{\left(a_{2}-x+\theta_{\tilde{a}}\left(x-a_{1}\right)\right)}{\left(a_{2}-a_{1}\right)} & \left(a_{1} \leq x \leq a_{2}\right) \\ \alpha_{\tilde{a}} & \left(a_{2} \leq x \leq a_{3}\right) \\ \frac{\left(x-a_{3}+\theta_{\tilde{a}}(a 4-x)\right)}{\left(a_{4}-a_{3}\right)} & \left(a_{3} \leq x \leq a_{4}\right) \\ 1 & \text { otherwise }\end{array}\right.$

$F_{\tilde{a}}(x)=\left\{\begin{array}{cc}\frac{\left(a_{2}-x+\beta_{\tilde{a}}\left(x-a_{1}\right)\right)}{\left(a_{2}-a_{1}\right)} & \left(a_{1} \leq x \leq a_{2}\right) \\ \alpha_{\tilde{a}} & \left(a_{2} \leq x \leq a_{3}\right) \\ \frac{\left(x-a_{3}+\beta_{\tilde{a}}(a 4-x)\right)}{\left(a_{4}-a_{3}\right)} & \left(a_{3} \leq x \leq a_{4}\right) \\ 1 & \text { otherwise, }\end{array}\right.$

where $\alpha_{\tilde{a}}, \theta_{\tilde{a}}$ and $\beta_{\tilde{a}}$ typify the maximum truth-membership degree, the minimum indeterminacy-membership degree and the minimum falsity-membership degree, respectively. A single valued trapezoidal neutrosophic number $\tilde{a}=\left\langle\left(a_{1}, a_{2}, a_{3}, a_{4}\right) ; \alpha_{\tilde{a}}, \theta_{\tilde{a}}, \beta_{\tilde{a}}\right\rangle$ may express an ill-defined quantity of the range, which is approximately equal to the interval $\left[a_{2}, a_{3}\right]$.

1. Definition 4. $[30,34]$ Let $\tilde{a}=\left\langle\left(a_{1}, a_{2}, a_{3}, a_{4}\right) ; \alpha_{\tilde{a}}, \theta_{\tilde{a}}, \beta_{\tilde{a}}\right\rangle$ and $\tilde{b}=$ $\left\langle\left(b_{1}, b_{2}, b_{3}, b_{4}\right) ; \alpha_{\tilde{b}}, \theta_{\tilde{b}}, \beta_{\tilde{b}}\right\rangle$ be two single valued trapezoidal neutrosophic numbers, and $\Upsilon \neq 0$ be any real number. Then: Addition of two trapezoidal neutrosophic numbers:

$$
\tilde{a}+\tilde{b}=\left\langle\left(a_{1}+b_{1}, a_{2}+b_{2}, a_{3}+b_{3}, a_{4}+b_{4}\right) ; \alpha_{\tilde{a}} \Lambda \alpha_{\tilde{b}}, \theta_{\tilde{a}} \vee \theta_{\tilde{b}}, \beta_{\tilde{a}} \vee \beta_{\tilde{b}}\right\rangle
$$

2. Subtraction of two trapezoidal neutrosophic numbers:

$\tilde{a}-\tilde{b}=\left\langle\left(a_{1}-b_{4}, a_{2}-b_{3}, a_{3}-b_{2}, a_{4}-b_{1}\right) ; \alpha_{\tilde{a}} \Lambda \alpha_{\tilde{b}}, \theta_{\tilde{a}} \vee \theta_{\tilde{b}}, \beta_{\tilde{a}} \vee \beta_{\tilde{b}}\right\rangle$ 
3. Inverse of trapezoidal neutrosophic numbers:

$$
\tilde{\mathbf{a}}-1=\left(\left(\frac{1}{a_{4}}, \frac{1}{a_{3}}, \frac{1}{a_{2}}, \frac{1}{a_{1}}\right) ; \alpha_{\tilde{a}}, \theta_{\tilde{a}}, \beta_{\tilde{a}}\right\rangle \text { where }(\tilde{a} \neq 0)
$$

4. Multiplication of trapezoidal neutrosophic numbers by constant value:

$$
\Upsilon \tilde{a}= \begin{cases}\left\langle\left(\Upsilon a_{1}, \Upsilon a_{2}, \Upsilon a_{3}, \Upsilon a_{4}\right) ; \alpha_{\tilde{a}}, \theta_{\tilde{a}}, \beta_{\tilde{a}}\right\rangle & \text { if }(\Upsilon>0) \\ \left\langle\left(\Upsilon a_{4}, \Upsilon a_{3}, \Upsilon a_{2}, \Upsilon a_{1}\right) ; \alpha_{\tilde{a}}, \theta_{\tilde{a}}, \beta_{\tilde{a}}\right\rangle & \text { if }(\Upsilon<0)\end{cases}
$$

5. Division of two trapezoidal neutrosophic numbers:

$$
\tilde{a} \tilde{b}= \begin{cases}\left\langle\left(\frac{a_{1}}{b_{4}}, \frac{a_{2}}{b_{3}}, \frac{a_{3}}{b_{2}}, \frac{a_{4}}{b_{1}}\right) ; \alpha_{\tilde{a}} \Lambda \alpha_{\tilde{b}}, \theta_{\tilde{a}} \vee \theta_{\tilde{b}}, \beta_{\tilde{a}} \vee \beta_{\tilde{b}}\right\rangle & \text { if }\left(a_{4}>0, b_{4}>0\right) \\ \left\langle\left(\frac{a_{4}}{b_{4}}, \frac{a_{3}}{b_{3}}, \frac{a_{2}}{b_{2}}, \frac{a_{1}}{b_{1}}\right) ; \alpha_{\tilde{a}} \Lambda \alpha_{\tilde{b}}, \theta_{\tilde{a}} \vee \theta_{\tilde{b}}, \beta_{\tilde{a}} \vee \beta_{\tilde{b}}\right\rangle & \text { if }\left(a_{4}<0, b_{4}>0\right) \\ \left\langle\left(\frac{a_{4}}{b_{1}}, \frac{a_{3}}{b_{2}}, \frac{a_{2}}{b_{3}}, \frac{a_{1}}{b_{4}}\right) ; \alpha_{\tilde{a}} \Lambda \alpha_{\tilde{b}}, \theta_{\tilde{a}} \vee \theta_{\tilde{b}}, \beta_{\tilde{a}} \vee \beta_{\tilde{b}}\right\rangle & \text { if }\left(a_{4}<0, b_{4}<0\right)\end{cases}
$$

6. Multiplication of trapezoidal neutrosophic numbers:

$$
\tilde{a} \tilde{b}= \begin{cases}\left\langle\left(a_{1} b_{1}, a_{2} b_{2}, a_{3} b_{3}, a_{4} b_{4}\right) ; \alpha_{\tilde{a}} \Lambda \alpha_{\tilde{b}}, \theta_{\tilde{a}} \vee \theta_{\tilde{b}}, \beta_{\tilde{a}} \vee \beta_{\tilde{b}}\right\rangle & \text { if }\left(a_{4}>0, b_{4}>0\right) \\ \left\langle\left(a_{1} b_{4}, a_{2} b_{3}, a_{3} b_{2}, a_{4} b_{1}\right) ; \alpha_{\tilde{a}} \Lambda \alpha_{\tilde{b}}, \theta_{\tilde{a}} \vee \theta_{\tilde{b}}, \beta_{\tilde{a}} \vee \beta_{\tilde{b}}\right\rangle & \text { if }\left(a_{4}<0, b_{4}>0\right) \\ \left\langle\left(a_{4} b_{4}, a_{3} b_{3}, a_{2} b_{2}, a_{1} b_{1}\right) ; \alpha_{\tilde{a}} \Lambda \alpha_{\tilde{b}}, \theta_{\tilde{a}} \vee \theta_{\tilde{b}}, \beta_{\tilde{a}} \vee \beta_{\tilde{b}}\right\rangle & \text { if }\left(a_{4}<0, b_{4}<0\right)\end{cases}
$$

\section{Neutrosophic set with robust ranking technique approach}

Smarandache [29] introduced the neutrosophic set theory. Neutrosophy addresses vagueness, uncertainty, and indeterminacy of values.

In this section, we give the steps of the proposed model based on the neutrosophic set and robust ranking technique, as presented in Fig. 2.

\subsection{The general steps of the proposed method}

Step 1: Collecting data about the status of destination.

1. Selecting three experts (the reviewer expert, the first expert and the second expert).

2. Identifying the relevant practices and performances used in green supply.

Step 2: Making pairwise comparison matrices between relevant practices and performances of green supply.

1. Identifying practices (RL, GD, GP, CM, SEC, ENP, ECP, CEC).

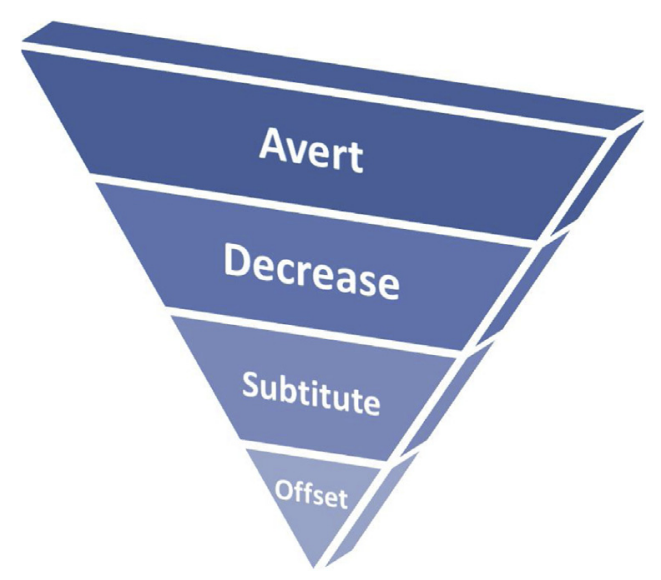

Fig. 2. Actions at the upper side have a major and permanent effect in decreasing the carbon footmark. a. Presenting each practice in order of a trapezoidal neutrosophic number $\left(l o_{x y}, m d_{x y}, m d_{x y}, u p_{x y}\right)$.

b. Making comparisons between practices by the first expert and the second expert, as presented in Table 2, and focusing on consensus judgments only on $(n-1)$ using a scale $(0,1)$ [35].

2. Determining the maximum truth-membership degree $(\alpha)$, the minimum indeterminacy-membership degree $(\beta)$ and the minimum falsity membership degree $(\theta)$ in matrices for the first and second expert, as shown in Table 3.

3. Calculating of the crisp values, as presented in Table 4, using the following formulas:

Score function:

$\mathrm{S}\left(\tilde{\mathrm{a}}_{i j}\right)=\frac{1}{16}\left[l o_{1}+m d_{1}+m d_{1}+u p_{1}\right] \times\left(2+\alpha_{\tilde{\mathbf{a}}}-\theta_{\tilde{\mathrm{a}}}-\beta_{\tilde{\mathrm{a}}}\right)$

Accuracy function:

$\mathrm{A}\left(\tilde{\mathrm{a}}_{i j}\right)=\frac{1}{16}\left[l o_{1}+m d_{1}+m d_{1}+u p_{1}\right] \times\left(2+\alpha_{\tilde{\mathbf{a}}}-\theta_{\tilde{\mathrm{a}}}+\beta_{\tilde{\mathrm{a}}}\right)$

Step 3: Calculating the average of all matrices.

Calculating the average for each row, firstly for the first expert, secondly for the second expert, as shown in Table 5, using Eq. (6).

$\operatorname{row}_{n m}=\frac{\operatorname{Crisp}_{1 n}+\operatorname{Crisp}_{2 n}+\ldots+C_{\text {rispV }} m}{n}$

Step 4: Merging of avg1 and avg2.

Merging of avg1 from expert 1 and of avg2 from expert 2 in [ $\tilde{A} \mathbf{U}$, $\tilde{A} \mathbf{L}]$, then putting the standard number in trapezoidal neutrosophic number, as presented in Table 6.

Step 5: Applying the robust ranking technique.

Lastly, we apply the robust ranking technique according to the following equations.

as $\tilde{A}=(\tilde{L}, a, b, \tilde{r})$

using of $\tilde{A}_{Y}=[\tilde{L}+(\mathrm{a}-\tilde{L}) \mathrm{y}, \tilde{r}-(\tilde{r}-\mathrm{b}) \mathrm{y}]$

$\mathrm{R}(\tilde{A})=\frac{1}{2} \int_{0}^{1}\left[\tilde{A}_{Y}^{L}, \tilde{A}_{Y}^{U}\right] d_{Y}$

$\mathrm{R}(\tilde{A})=\frac{1}{2} \int_{0}^{1}[(\tilde{L}+(\mathrm{a}-\tilde{L}) y),+(\tilde{r}-(\tilde{r}-b) y)] d_{Y}$

where $\mathrm{y}=[0,1]$.

Step 6: Drawing diagram of the result.

- Making the decision.

\section{An Illustrative example}

In this section, we describe the proposed method for evolving green practices in a green supply chain using robust ranking with neutrosophic set. This section has three subsections: (1) the case study, (2) the calculation process, (3) the analysis of practices (Figs. 3-7).

\subsection{Case study one}

The General Petroleum Company - GPC operates in the Egyptian petroleum sector, which was established in 1957 as a state-owned company ("public sector"), with a paid-up of LE 498 
Table 2

The pairwise comparison matrix between practices and performances selected from green supply.

\begin{tabular}{|c|c|c|c|c|}
\hline Practice & RL & GD & GP, CM, SEC, CEC, ENP & $\mathrm{ECP}$ \\
\hline RL & $\left(l_{11}, m d_{11 l}, m d_{11 u}, u p_{11}\right)$ & $\left(l_{12}, m d_{12 l}, m_{12 u}, u p_{12}\right)$ & $\ldots$ & $\left(l o_{1 n}, m d_{1 n l}, m d_{1 n u}, u p_{1 n}\right)$ \\
\hline GD & $\left(l_{21}, m d_{21 l}, m d_{21 u}, u p_{21}\right)$ & $\left(l_{22}, m d_{22 l}, m d_{22 u}, u p_{22}\right)$ & $\ldots$ & $\left(l_{2 n}, m d_{2 n l}, m d_{2 n u}, u p_{2 n}\right)$ \\
\hline GP, CM, SEC, CEC, ENP & $\ldots$ & $\ldots$ & $\ldots$ & $\ldots$ \\
\hline ECP & $\left(l o_{n 1}, m d_{n 1 l}, m d_{n 1 u}, u p_{n 1}\right)$ & $\left(l_{n 2}, m d_{n 2 l}, m d_{n 2 u}, u p_{n 2}\right)$ & $\ldots$ & $\left(l o_{n n}, m d_{n n l}, m d_{n n u}, u p_{n n}\right)$ \\
\hline
\end{tabular}

Table 3

The $\alpha, \beta$ and $\theta$ degree in comparison matrix between practices.

\begin{tabular}{|c|c|c|c|c|}
\hline Practice & RL & GD & GP, CM, SEC, CEC, ENP & ECP \\
\hline RL & $\left(l_{11}, m d_{11 l}, m d_{11 u}, u p_{11} ; \alpha, \beta, \theta\right)$ & $\left(l o_{12}, m d_{12 l}, m d_{12 u}, u p_{12} ; \alpha, \beta, \theta\right)$ & $\ldots$ & $\left(l_{o_{1 n}}, m d_{1 n l}, m d_{1 n u}, u p_{1 n} ; \alpha, \beta, \theta\right)$ \\
\hline GD & $\left(l_{21}, m d_{21 l}, m d_{21 u}, u p_{21} ; \alpha, \beta, \theta\right)$ & $\left(l_{22}, m d_{22 l}, m d_{22 u}, u p_{22} ; \alpha, \beta, \theta\right)$ & $\ldots$ & $\left(l_{2 n}, m d_{2 n l}, m d_{2 n u}, u p_{2 n} ; \alpha, \beta, \theta\right)$ \\
\hline GP, CM, SEC, CEC, ENP & . & $\ldots$ & $\ldots$ & $\ldots$ \\
\hline ECP & $\left(l o_{n 1}, m d_{n 1 l}, m d_{n 1 u}, u p_{n 1} ; \alpha, \beta, \theta\right)$ & $\left(l o_{n 2}, m d_{n 2 l}, m d_{n 2 u}, u p_{n 2} ; \alpha, \beta, \theta\right)$ & $\ldots$ & $\left(l_{n n}, m d_{n n l}, m d_{n n u}, u p_{n n} ; \alpha, \beta, \theta\right)$ \\
\hline
\end{tabular}

Table 4

The result of crisp values of matrices.

\begin{tabular}{|c|c|c|c|c|}
\hline Practice & RL & GD & GP, CM, SEC, CEC, ENP & ECP \\
\hline RL & CrispV $_{11}$ & CrispV $_{21}$ & $\ldots$ & CrispV $_{m 1}$ \\
\hline GD & CrispV $_{12}$ & CrispV $_{22}$ & $\ldots$ & $C$ risp $V_{m 2}$ \\
\hline GP, CM, SEC, CEC, ENP & $\ldots$ & $\ldots$ & $\ldots$ & $\ldots$ \\
\hline ECP & CrispV $_{1 n}$ & CrispV $_{2 n}$ & $\ldots$ & CrispV $_{m n}$ \\
\hline
\end{tabular}

Table 5

Calculating the average for each row.

\begin{tabular}{ll}
\hline Practice name & Avg. \\
\hline RL & Value \\
GD & Value \\
GP & Value \\
CM & Value \\
SEC & Value \\
CEC & Value \\
ENP & Value \\
ECP & Value \\
\hline
\end{tabular}

Table 6

Putting the standard number in trapezoidal neutrosophic number.

\begin{tabular}{lllll}
\hline Practice name & Expert 1 Avg. & Expert 2 Avg. & {$[\tilde{A} U, \tilde{A} L]$} & $(\tilde{L}, a, b, \tilde{r})$ \\
\hline RL & & & $\ldots$ \\
GD & & & $\ldots$ \\
GP & & & \\
CM & & & \\
SCE & & & \\
CEC & & & \\
ENP & $\ldots$ & $\ldots$ & $\ldots$ & $\ldots$ \\
ECP & & & \\
\hline
\end{tabular}

million, owned by the Egyptian General Petroleum Authority (EGPC), in order to be the first national company engaged in the research and production of oil in Egypt. The company aims to explore, produce and develop oil and gas fields to maximize reserves and returns to partners through optimal economic exploitation of available resources, technology and modern management methods. In 2015, GPC produced nearly 4 million barrels per day and planned to rise its annual capacity to 5 million fuel barrels. Since 2015, General Petroleum Company is the dominant player in the Middle East, producing fuel barrels share of nearly 40\%. GSCM is still a relatively new concept in Egypt; despite the legal obligations, many businesses still weight the significance of GSCM. However, GPC plans to implement green practices at all

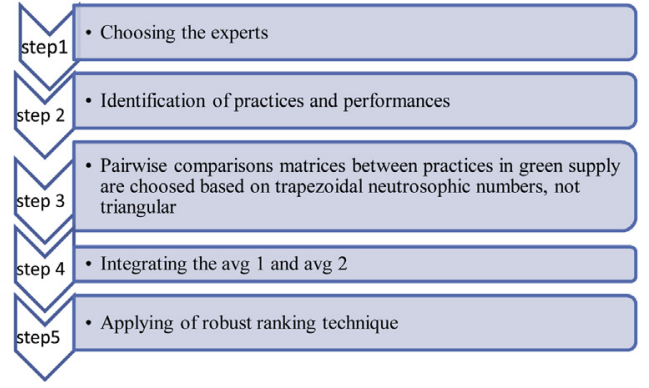

Fig. 3. The General steps for the proposed method.

levels of the production process as a proactive approach to gain profit and market share by reducing environmental leverage and improving ecological efficiency. The government has encouraged environmental co-partnership by supporting organizations to start and improve their GSCM. Hence, to consider and develop GSCM practices and performances, General Petroleum Company was selected as case study.

\subsection{The calculation process of the neutrosophic set using robust ranking technique}

Every company should consider developing in growth of green supply. Nowadays, any company seeks to apply green supply practices and performances at all levels of production, as a proactive approach in order to attain profit, but at the same time reducing environmental impact. In this paper, we determine some green supply categories. There are many green supply practices that we deal with: green practices: $\mathrm{RL}=$ reverse logistics; $\mathrm{GD}=$ green design; $\mathrm{GP}=$ green purchasing; $\mathrm{CM}=$ carbon management; SEC = supplier environmental collaboration; ENP = environmental performance; $\mathrm{ECP}=$ economic performance; $\mathrm{CEC}=$ customer environmental collaboration. Therefore, we need to understand every components of green practices and how they affect one another, by making a matrix for these components. In the last section, we compared matrices to evaluate each criterion based on points of views from experts, using the neutrosophic scale of 0,1 . In order to collect data, we interviewed three professional experts (one of them being expert in research and environmental management, another being expert in logistics and development, and the last one, to review the other two experts' opinions). The data collected from the three experts were analyzed by neutrosophic set and robust ranking method. The steps that were conducted are the following: 


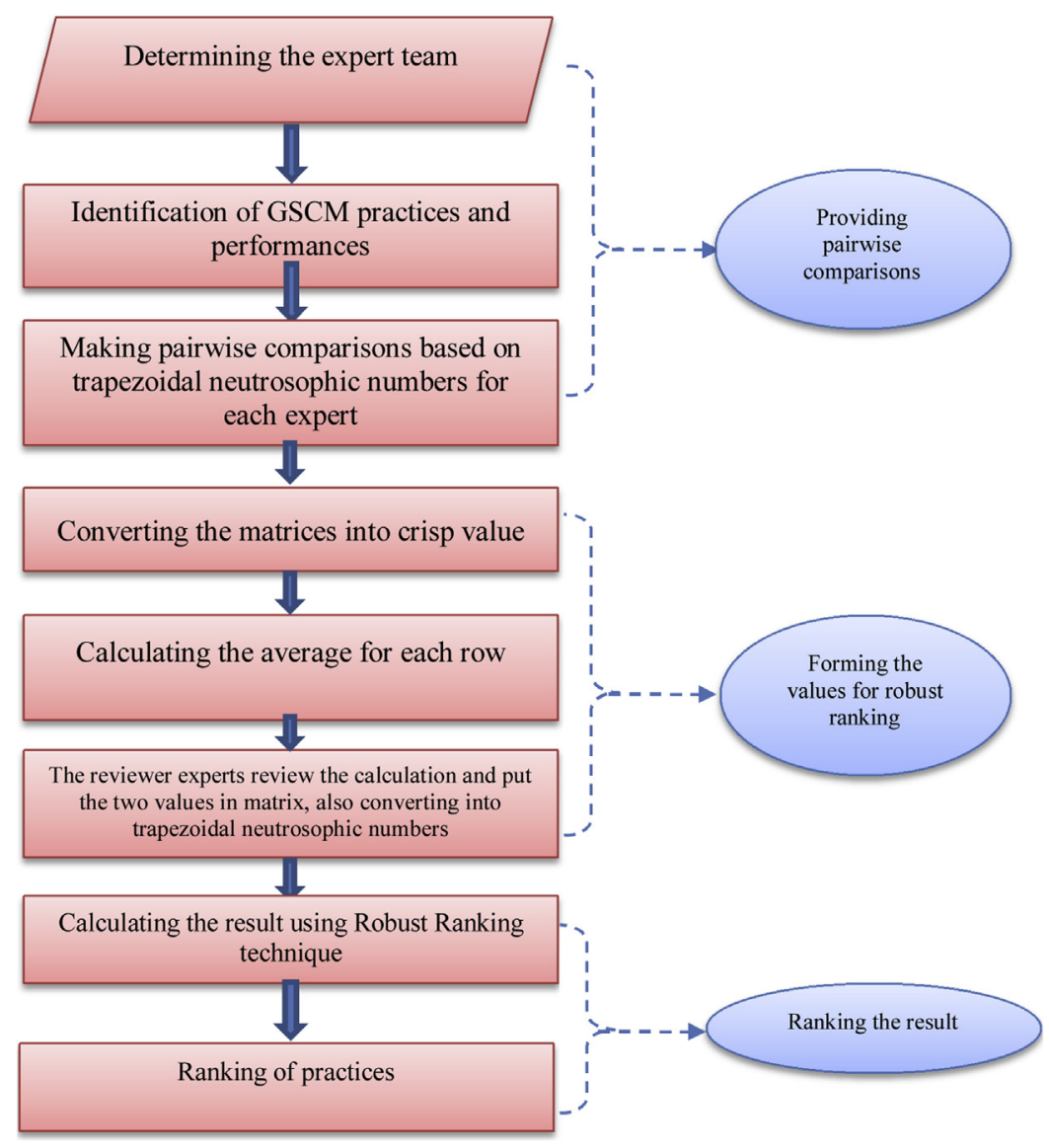

Fig. 4. Schematic diagram of using robust ranking in neutrosophic environment.

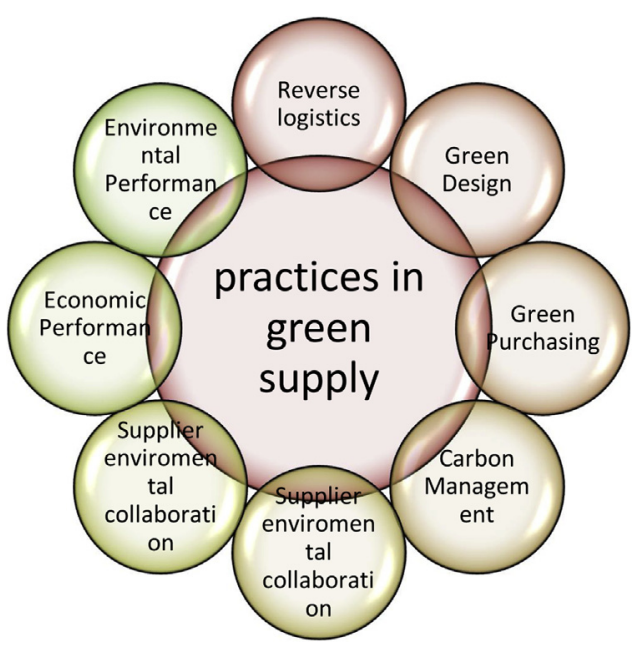

Fig. 5. Main practices in green supply.

Step 1. Choosing the experts.

In this step, we selected the group of experts consisting in three experts (the reviewer expert, the first expert and the second expert).

Step 2. Identification of practices and performances.

We sorted out seven evaluation criteria as selected by the team of experts, namely: green practices: $\mathrm{RL}=$ reverse logistics; $\mathrm{GD}=$ green design; $\mathrm{GP}=$ green purchasing; $\mathrm{CM}=$ carbon management; SEC = supplier environmental collaboration;

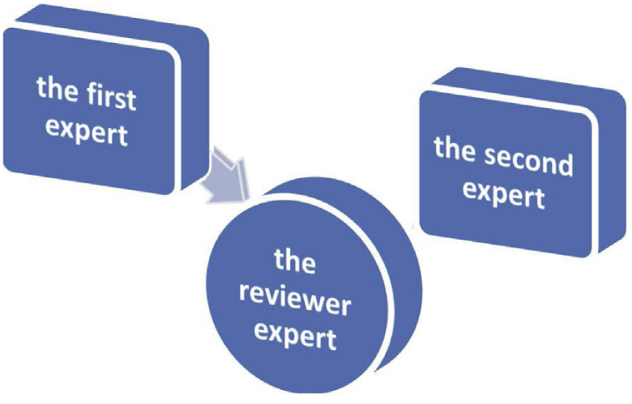

Fig. 6. Group of experts.

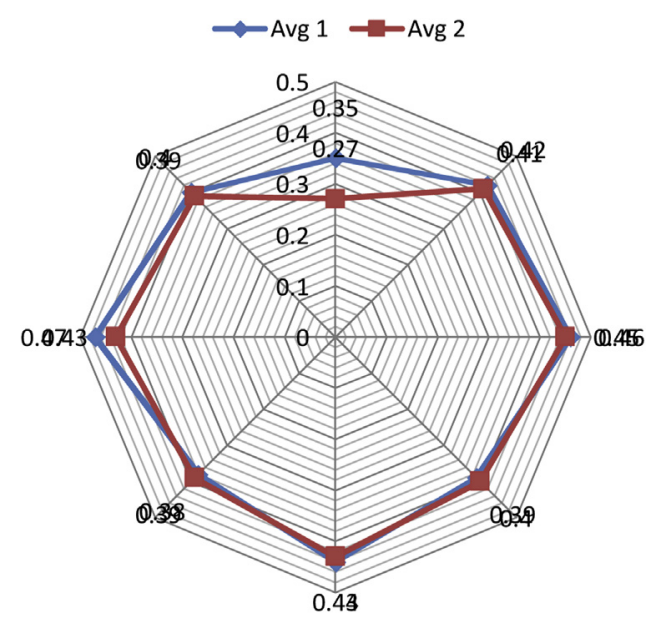

Fig. 7. The result of comparing average. 
Table 7

Linguistic terms and the identical trapezoidal neutrosophic numbers.

\begin{tabular}{ll}
\hline Linguistic term & Neutrosophic Trapezoidal Scale \\
\hline Absolutely low influence & $\langle(0.1,0.1,0.1,0.1) ; 0.5,0.3,0.3\rangle$ \\
Low influence & $\langle(0.2,0.3,0.4,0.5) ; 0.6,0.2,0.2\rangle$ \\
Slightly low influence & $\langle(0.3,0.4,0.5,0.6) ; 0.7,0.1,0.1\rangle$ \\
Fairly low influence & $\langle(0.4,0.5,0.6,0.7) ; 0.8,0.0,0.1\rangle$ \\
Medium influence & $\langle(0.5,0.6,0.7,0.8) ; 0.7,0.3,0.3\rangle$ \\
Fairly high influence & $\langle(0.6,0.7,0.8,0.9) ; 0.8,0.2,0.30\rangle$ \\
High influence & $\langle(0.7,0.8,0.9,1.0) ; 0.9,0.1,0.1\rangle$ \\
Very strong influence & $\langle(0.8,0.9,1.0,1.0) ; 0.9,0.0,0.1\rangle$ \\
Absolutely high influence & $\langle(1.0,1.0,1.0,1.0) ; 1.00,0.00,0.00\rangle$ \\
\hline
\end{tabular}

Table 8

Linguistic variables for experts.

\begin{tabular}{ll}
\hline Linguistic variable & Trapezoidal Numbers \\
\hline Very low (VL) & $\langle(0.0,0.1,0.2,0.1)\rangle$ \\
Low (L) & $\langle(0.1,0.3,0.4,0.5)\rangle$ \\
Medium (M) & $\langle(0.3,0.4,0.5,0.7)\rangle$ \\
High $(\mathrm{H})$ & $\langle(0.5,0.7,0.6,0.9)\rangle$ \\
Very High $(\mathrm{VH})$ & $\langle(0.7,0.6,0.9,1.0)\rangle$ \\
\hline
\end{tabular}

$\mathrm{ENP}=$ environmental performance; $\mathrm{ECP}=$ economic performance; $\mathrm{CEC}=$ customer environmental collaboration .

Step 3. Formation of pairwise comparisons matrices between practices in green supply are based on trapezoidal neutrosophic numbers, not triangular numbers.

1. Using of the linguistic terms and linguistic variables, as shown in Tables 7-9.

2. Pairwise comparisons matrices to evaluate each practice and performance in green supply against each other, as shown in Tables 10 and 14.

3. Determining of membership, the maximum truth membership degree $(\alpha)$, the minimum indeterminacy membership degree $(\theta)$ and the minimum falsity membership degree $(\beta)$, developed by experts, as shown in Tables 11 and 15.

4. Calculating the crisp value for each matrix applied by every expert, as shown in Tables 12 and 16.

5. Calculating the average of each row in all matrices for each expert, as shown in Tables 13 and 17 (Tables 14-16).

Step 4. Integrating the avg 1 and avg 2 .

We integrate the values of Tables 13 and 17 as lower and upper value $[\tilde{A} \mathbf{U}, \tilde{A} \mathbf{L}]$; then, the reviewer expert reviews the results from

Table 9

Importance weight for experts.

\begin{tabular}{|c|c|c|c|}
\hline Experts & Linguistic variable & Importance weights & Crisp weights \\
\hline Expert 1(Log. and dev. purchasing) & Medium & $\langle(0.3,0.4,0.5,0.7)\rangle$ & 0.4 \\
\hline Expert 2 (Res. and environmental manag.) & High & $\langle(0.5,0.7,0.6,0.9)\rangle$ & 0.7 \\
\hline Expert 3 (Reviewer) & Medium & $\langle(0.3,0.4,0.5,0.7)\rangle$ & 0.4 \\
\hline
\end{tabular}

Table 10

Relation matrix (Data collected from expert in Logistics and development, purchasing).

\begin{tabular}{|c|c|c|c|c|c|c|c|c|}
\hline Practice name & RL & GD & GP & $\mathrm{CM}$ & SEC & CEC & ENP & ECP \\
\hline RL & $(0.5,0.5,0.5,0.5)$ & $(0.8,0.9,1.0,1.0)$ & $(0.7,0.8,0.9,1.0)$ & $(0.6,0.7,0.8,0.9)$ & $(0.1,0.1,0.1,0.1)$ & $(0.2,0.3,0.4,0.5)$ & $(0.5,0.6,0.7,0.8)$ & $(0.1,0.1,0.1,0.1)$ \\
\hline GD & $(0.2,0.3,0.4,0.5)$ & $(0.5,0.5,0.5,0.5)$ & $(0.4,0.5,0.6,0.7)$ & $(0.5,0.6,0.7,0.8)$ & $(0.7,0.8,0.9,1.0)$ & $(0.2,0.3,0.5,0.7)$ & $(0.8,0.9,1.0,1.0)$ & $(0.7,0.8,0.9,1.0)$ \\
\hline GP & $(1.0,1.0,1.0,1.0)$ & $(0.1,0.1,0.1,0.1)$ & $(0.5,0.5,0.5,0.5)$ & $(0.8,0.9,1.0,1.0)$ & $(0.3,0.4,0.5,0.6)$ & $(1.0,1.0,1.0,1.0)$ & $(0.5,0.6,0.7,0.8)$ & $(0.4,0.5,0.6,0.7)$ \\
\hline $\mathrm{CM}$ & $(0.3,0.4,0.5,0.6)$ & $(0.5,0.6,0.7,0.8)$ & $(0.3,0.4,0.5,0.6)$ & $(0.5,0.5,0.5,0.5)$ & $(0.7,0.8,0.9,1.0)$ & $(0.3,0.4,0.5,0.6)$ & $(0.6,0.7,0.8,0.9)$ & $(0.6,0.7,0.8,0.9)$ \\
\hline SEC & $(0.7,0.8,0.9,1.0)$ & $(0.6,0.7,0.8,0.9)$ & $(1.0,1.0,1.0,1.0)$ & $(0.1,0.1,0.1,0.1)$ & $(0.5,0.5,0.5,0.5)$ & $(0.7,0.8,0.9,1.0)$ & $(0.4,0.5,0.6,0.7)$ & $(0.3,0.4,0.5,0.6)$ \\
\hline CEC & $(0.4,0.5,0.6,0.7)$ & $(0.4,0.5,0.6,0.7)$ & $(0.3,0.4,0.5,0.6)$ & $(0.5,0.6,0.7,0.8)$ & $(0.4,0.5,0.6,0.7)$ & $(0.5,0.5,0.5,0.5)$ & $(0.7,0.8,0.9,1.0)$ & $(0.5,0.6,0.7,0.8)$ \\
\hline ENP & $(0.6,0.7,0.8,0.9)$ & $(0.7,0.8,0.9,1.0)$ & $(0.7,0.8,0.9,1.0)$ & $(0.6,0.7,0.8,0.9)$ & $(0.3,0.4,0.5,0.6)$ & $(0.4,0.5,0.6,0.7)$ & $(0.5,0.5,0.5,0.5)$ & $(0.8,0.9,1.0,1.0)$ \\
\hline ECP & $(0.5,0.6,0.7,0.8)$ & $(0.3,0.4,0.5,0.6)$ & $(0.4,0.5,0.6,0.7)$ & $(0.4,0.5,0.6,0.7)$ & $(0.7,0.8,0.9,1.0)$ & $(0.6,0.7,0.8,0.9)$ & $(0.3,0.4,0.5,0.6)$ & $(0.5,0.5,0.5,0.5)$ \\
\hline
\end{tabular}

Table 11 Relation matrix between operators with the $\alpha, \beta$ and $\theta$ degrees

\begin{tabular}{|c|c|c|c|c|c|c|c|c|}
\hline $\begin{array}{l}\text { Practice } \\
\text { name }\end{array}$ & $\mathrm{RL}$ & GD & GP & $\mathrm{CM}$ & SEC & CEC & ENP & ECP \\
\hline RL & $(0.5,0.5,0.5,0.5)$ & $\left(\begin{array}{c}0.8,0.9,1.0,1.0 \\
; .9, .1, .1\end{array}\right)$ & $\left(\begin{array}{c}(0.7,0.8,0.9,1.0) \\
; .9, .1, .1\end{array}\right)$ & $\left(\begin{array}{c}0.6,0.7,0.8,0.9 \\
; .8,2, .3\end{array}\right)$ & $\left(\begin{array}{c}0.1,0.1,0.1,0.1 \\
; .5, .3, .3\end{array}\right)$ & $\left(\begin{array}{c}0.2,0.3,0.4,0.5 \\
: .6, .2, .2)\end{array}\right)$ & $\left(\begin{array}{c}0.5,0.6,0.7,0.8 \\
.7,3.3\end{array}\right)$ & $\left(\begin{array}{c}0.1,0.1,0.1,0.1 \\
: 5, .3,3\end{array}\right)$ \\
\hline GD & $\left(\begin{array}{c}0.2,0.3,0.4,0.5 \\
; .6, .2, .2)\end{array}\right)$ & $(0.5,0.5,0.5,0.5)$ & $\left(\begin{array}{c}0.4,0.5,0.6,0.7 \\
; .8,0, .1\end{array}\right)$ & $\left(\begin{array}{c}0.5,0.6,0.7,0.8 \\
; .7, .3, .3\end{array}\right)$ & $\left(\begin{array}{c}0.7,0.8,0.9,1.0 \\
; .9, .1, .1)\end{array}\right)$ & $\left(\begin{array}{c}0.2,0.3,0.5,0.7 \\
; .6, .2, .2\end{array}\right)$ & $\left(\begin{array}{c}0.8,0.9,1.0,1.0 \\
; .9, .1, .1\end{array}\right)$ & $\left(\begin{array}{c}0.7,0.8,0.9,1.0 \\
; .9, .1, .1)\end{array}\right)$ \\
\hline GP & $\left(\begin{array}{c}1.0,1.0,1.0,1.0 \\
; 1.0,0,0\end{array}\right)$ & $\left(\begin{array}{c}0.1,0.1,0.1,0.1 \\
; .5, .3, .3\end{array}\right)$ & $(0.5,0.5,0.5,0.5)$ & $\left(\begin{array}{c}0.8,0.9,1.0,1.0 \\
; .9, .1, .1\end{array}\right)$ & $\left(\begin{array}{c}0.3,0.4,0.5,0.6 \\
; .7, .1, .1\end{array}\right)$ & $\left(\begin{array}{c}1.0,1.0,1.0,1.0 \\
; 1.0,0,0\end{array}\right)$ & $\left(\begin{array}{c}0.5,0.6,0.7,0.8 \\
; .7, .3, .3\end{array}\right)$ & $\left(\begin{array}{c}0.4,0.5,0.6,0.7 \\
; .8,0, .1\end{array}\right)$ \\
\hline CM & $\left(\begin{array}{c}0.3,0.4,0.5,0.6 \\
; .7, .1, .1\end{array}\right)$ & $\left(\begin{array}{c}0.5,0.6,0.7,0.8 \\
; .7, .3, .3\end{array}\right)$ & $\left(\begin{array}{c}0.3,0.4,0.5,0.6 \\
; .7, .1, .1\end{array}\right)$ & $(0.5,0.5,0.5,0.5)$ & $\left(\begin{array}{c}0.7,0.8,0.9,1.0 \\
; .9, .1, .1)\end{array}\right)$ & $\left(\begin{array}{c}0.3,0.4,0.5,0.6 \\
; .7, .1, .1\end{array}\right)$ & $\left(\begin{array}{c}0.6,0.7,0.8,0.9 \\
; .8, .2, .3\end{array}\right)$ & $\left(\begin{array}{c}0.6,0.7,0.8,0.9 \\
; .8,2 . .3\end{array}\right)$ \\
\hline SEC & $\left(\begin{array}{c}(0.7,0.8,0.9,1.0 \\
; .9, .1, .1)\end{array}\right)$ & $\left(\begin{array}{c}0.6,0.7,0.8,0.9 \\
; .8,2, .3\end{array}\right)$ & $\left(\begin{array}{c}1.0,1.0,1.0,1.0 \\
; 1.0,0,0\end{array}\right)$ & $\left(\begin{array}{c}0.1,0.1,0.1,0.1 \\
; .5, .3, .3\end{array}\right)$ & $(0.5,0.5,0.5,0.5)$ & $\left(\begin{array}{c}0.7,0.8,0.9,1.0 \\
; .9, .1, .1)\end{array}\right)$ & $\left(\begin{array}{c}0.4,0.5,0.6,0.7 \\
; .8,0, .1\end{array}\right)$ & $\left(\begin{array}{c}0.3,0.4,0.5,0.6 \\
; .7, .1, .1\end{array}\right)$ \\
\hline CEC & $\left(\begin{array}{c}0.4,0.5,0.6,0.7 \\
; .8,0, .1\end{array}\right)$ & $\left(\begin{array}{c}0.4,0.5,0.6,0.7 \\
; .8,0, .1\end{array}\right)$ & $\left(\begin{array}{c}0.3,0.4,0.5,0.6 \\
; .7, .1, .1\end{array}\right)$ & $\left(\begin{array}{c}0.5,0.6,0.7,0.8 \\
; .7, .3, .3\end{array}\right)$ & $\left(\begin{array}{c}0.4,0.5,0.6,0.7 \\
; .8,0, .1\end{array}\right)$ & $(0.5,0.5,0.5,0.5)$ & $\left(\begin{array}{c}0.7,0.8,0.9,1.0 \\
; .9, .1, .1)\end{array}\right)$ & $\left(\begin{array}{c}0.5,0.6,0.7,0.8 \\
; .7, .3, .3\end{array}\right)$ \\
\hline ENP & $\left(\begin{array}{c}0.6,0.7,0.8,0.9 \\
; .8, .2, .3\end{array}\right)$ & $\left(\begin{array}{c}(0.7,0.8,0.9,1.0 \\
; .9, .1,1)\end{array}\right)$ & $\left(\begin{array}{c}(0.7,0.8,0.9,1.0 \\
; .9, .1, .1)\end{array}\right)$ & $\left(\begin{array}{c}0.6,0.7,0.8,0.9 \\
; .8, .2, .3\end{array}\right)$ & $\left(\begin{array}{c}0.3,0.4,0.5,0.6 \\
; .7, .1, .1\end{array}\right)$ & $\left(\begin{array}{c}0.4,0.5,0.6,0.7 \\
; .8,0, .1\end{array}\right)$ & $(0.5,0.5,0.5,0.5)$ & $\left(\begin{array}{c}0.8,0.9,1.0,1.0 \\
; .9, .1, .1\end{array}\right)$ \\
\hline $\mathrm{ECP}$ & $\left(\begin{array}{c}0.5,0.6,0.7,0.8 \\
; .7, .3, .3\end{array}\right)$ & $\left(\begin{array}{c}0.3,0.4,0.5,0.6 \\
; .7, .1, .1\end{array}\right)$ & $\left(\begin{array}{c}0.4,0.5,0.6,0.7 \\
; .8,0, .1\end{array}\right)$ & $\left(\begin{array}{c}0.4,0.5,0.6,0.7 \\
; .8,0, .1\end{array}\right)$ & $\left(\begin{array}{c}0.7,0.8,0.9,1.0 \\
; .9, .1, .1)\end{array}\right)$ & $\left(\begin{array}{c}0.6,0.7,0.8,0.9 \\
; .8, .2, .3\end{array}\right)$ & $\left(\begin{array}{c}0.3,0.4,0.5,0.6 \\
; .7, .1, .1\end{array}\right)$ & $(0.5,0.5,0.5,0.5)$ \\
\hline
\end{tabular}


Table 12 The crisp values of relation matrix

\begin{tabular}{lllllllll}
\hline Practice name & RL & GD & GP & CM & SEC & CEC & ENP & ECP \\
\hline RL & 0.500 & 0.624 & 0.574 & 0.431 & 0.048 & 0.193 & 0.341 & 0.048 \\
GD & 0.193 & 0.500 & 0.371 & 0.341 & 0.574 & 0.193 & 0.624 & 0.574 \\
GP & 0.750 & 0.048 & 0.500 & 0.624 & 0.281 & 0.750 & 0.341 & 0.371 \\
CM & 0.281 & 0.341 & 0.281 & 0.500 & 0.574 & 0.281 & 0.431 & 0.431 \\
SEC & 0.574 & 0.431 & 0.750 & 0.048 & 0.500 & 0.574 & 0.371 & 0.281 \\
CEC & 0.371 & 0.371 & 0.281 & 0.341 & 0.371 & 0.500 & 0.574 & 0.341 \\
ENP & 0.431 & 0.574 & 0.574 & 0.431 & 0.281 & 0.371 & 0.500 & 0.624 \\
ECP & 0.341 & 0.281 & 0.371 & 0.371 & 0.574 & 0.431 & 0.281 & 0.500 \\
\hline
\end{tabular}

Table 13 The row average of matrix

\begin{tabular}{lc}
\hline Practice name & Avg. \\
\hline RL & 0.35 \\
GD & 0.42 \\
GP & 0.46 \\
CM & 0.39 \\
SEC & 0.44 \\
CEC & 0.38 \\
ENP & 0.47 \\
ECP & 0.40 \\
\hline
\end{tabular}

expert 1 and expert 2, and put these values in trapezoidal neutrosophic numbers (Tables 18 and 19).

Step 5. Applying of robust ranking technique.

We apply the equation (robust ranking) to obtain the value of $\mathrm{R}$ $(\tilde{A})$, then ordering operators using robust ranking.

Step 6. Drawing diagram of the result.

The diagram depicted in Fig. 8 ranking of the result.

\subsection{Analyzing the practices in green supply}

In this case study, we integrate and analyze the collected data from three experts (the reviewer expert, the first expert and the second expert). The aim is to find out the evaluation of practices and performances in green supply. Our results can determine the most important practices that should be developed from the chart in Fig. 8, the lowest value of practices and performances in green supply in this case is the Reverse Logistics (RL), and the highest value is Green Purchasing (GP).

\section{Another supporting case study in China}

This section presents another supporting case study to illustrate how our work can make direct research contributions independent of countries and locations. A green manufacturing firm was closely involved. They followed our recommendations and we then presented the results and analysis. Frim A is a manufacturing supplier for automated machineries in Suzhou, China. Suzhou Industrial Park (SIP) is a well-known industry area that has contributed significantly to the economic development of Suzhou, which has become one of the new first tier cities in China. Firm A manufactures automated machines, which can work efficiently and more than $16 \mathrm{~h}$ a day for building components, making parts of the products and assembling components into products. They employed more than 400 people. The automated machineries and its product-making processes make very low carbon production. The products are very environmentally friendly, since they use intelligent algorithms to increase productivity and reduce generation of a lot of carbon dioxide after the end of each manufacturing process. We followed all the steps in Section 5. The only difference is that we keep track of the improvements over a period of six months. It is important to measure the benefits before and after adopting our proposal. The aim is to identify the level of

Table 14 Relation Matrix (Data collected from expert in Research and Environmental Management)

\begin{tabular}{|c|c|c|c|c|c|c|c|c|}
\hline Practice name & RL & GD & GP & $\mathrm{CM}$ & SEC & CEC & ENP & ECP \\
\hline $\mathrm{RL}$ & $(0.5,0.5,0.5,0.5)$ & $(0.2,0.3,0.4,0.5)$ & $(1.0,1.0,1.0,1.0)$ & $(0.3,0.4,0.5,0.6)$ & $(0.7,0.8,0.9,1.0)$ & $(0.4,0.5,0.6,0.7)$ & $(0.6,0.7,0.8,0.9)$ & $(0.5,0.6,0.7,0.8)$ \\
\hline GD & $(0.2,0.3,0.4,0.5)$ & $(0.5,0.5,0.5,0.5)$ & $(0.4,0.5,0.6,0.7)$ & $(0.5,0.6,0.7,0.8)$ & $(0.7,0.8,0.9,1.0)$ & $(0.2,0.3,0.5,0.7)$ & $(0.3,0.4,0.5,0.6)$ & $(0.7,0.8,0.9,1.0)$ \\
\hline GP & $(1.0,1.0,1.0,1.0)$ & $(1.0,1.0,1.0,1.0)$ & $(0.5,0.5,0.5,0.5)$ & $(0.7,0.8,0.9,1.0)$ & $(0.8,0.9,1.0,1.0)$ & $(0.3,0.4,0.5,0.6)$ & $(0.5,0.6,0.7,0.8)$ & $(0.8,0.9,1.0,1.0)$ \\
\hline $\mathrm{CM}$ & & $(0.5,0.6,0.7,0.8)$ & $(0.3,0.4,0.5,0.6)$ & $(0.5,0.5,0.5,0.5)$ & $(0.7,0.8,0.9,1.0)$ & $(0.3,0.4,0.5,0.6)$ & $(0.6,0.7,0.8,0.9)$ & $(0.6,0.7,0.8,0.9)$ \\
\hline SEC & $(0.7,0.8,0.9,1.0)$ & $(0.6,0.7,0.8,0.9)$ & $(0.3,0.4,0.5,0.6)$ & $(1.0,1.0,1.0,1.0)$ & $(0.5,0.5,0.5,0.5)$ & $(0.7,0.8,0.9,1.0)$ & $(0.4,0.5,0.6,0.7)$ & $(0.8,0.9,1.0,1.0)$ \\
\hline CEC & $(0.4,0.5,0.6,0.7)$ & $(0.7,0.8,0.9,1.0)$ & $(0.3,0.4,0.5,0.6)$ & $(0.5,0.6,0.7,0.8)$ & $(0.4,0.5,0.6,0.7)$ & $(0.5,0.5,0.5,0.5)$ & $(0.7,0.8,0.9,1.0)$ & $(0.5,0.6,0.7,0.8)$ \\
\hline ENP & $(0.8,0.9,1.0,1.0)$ & $(0.3,0.4,0.5,0.6)$ & $(0.7,0.8,0.9,1.0)$ & $(0.6,0.7,0.8,0.9)$ & $(1.0,1.0,1.0,1.0)$ & $(0.7,0.8,0.9,1.0)$ & $(0.5,0.5,0.5,0.5)$ & $(0.8,0.9,1.0,1.0)$ \\
\hline ECP & $(0.5,0.6,0.7,0.8)$ & $(0.3,0.4,0.5,0.6)$ & $(0.4,0.5,0.6,0.7)$ & $(0.4,0.5,0.6,0.7)$ & $(0.7,0.8,0.9,1.0)$ & $(0.6,0.7,0.8,0.9)$ & $(0.3,0.4,0.5,0.6)$ & $(0.5,0.5,0.5,0.5)$ \\
\hline
\end{tabular}

Table 15 Relation matrix between operators with the $\alpha, \beta$ and $\theta$ degrees

\begin{tabular}{|c|c|c|c|c|c|c|c|c|}
\hline $\begin{array}{l}\text { Practice } \\
\text { name }\end{array}$ & RL & GD & GP & $\mathrm{CM}$ & SEC & CEC & ENP & ECP \\
\hline RL & $(0.5,0.5,0.5,0.5)$ & $\left(\begin{array}{c}0.8,0.9,1.0,1.0 \\
; .9, .1, .1\end{array}\right)$ & $\left(\begin{array}{c}(0.7,0.8,0.9,1.0) \\
; .9, .1, .1\end{array}\right)$ & $\left(\begin{array}{c}0.6,0.7,0.8,0.9 \\
; .8,2, .3\end{array}\right)$ & $\left(\begin{array}{c}0.1,0.1,0.1,0.1 \\
; .5, .3, .3\end{array}\right)$ & $\left(\begin{array}{c}0.2,0.3,0.4,0.5 \\
; .6, .2, .2)\end{array}\right)$ & $\left(\begin{array}{c}0.5,0.6,0.7,0.8 \\
; .7, .3, .3\end{array}\right)$ & $\left(\begin{array}{c}0.1,0.1,0.1,0.1 \\
; .5, .3, .3\end{array}\right)$ \\
\hline GD & $\left(\begin{array}{c}0.2,0.3,0.4,0.5 \\
; .6, .2, .2)\end{array}\right)$ & $(0.5,0.5,0.5,0.5)$ & $\left(\begin{array}{c}0.4,0.5,0.6,0.7 \\
; .8,0, .1\end{array}\right)$ & $\left(\begin{array}{c}0.5,0.6,0.7,0.8 \\
; .7,3, .3\end{array}\right)$ & $\left(\begin{array}{c}0.7,0.8,0.9,1.0 \\
; .9, .1, .1)\end{array}\right)$ & $\left(\begin{array}{c}0.2,0.3,0.5,0.7 \\
; .6, .2, .2\end{array}\right)$ & $\left(\begin{array}{c}0.8,0.9,1.0,1.0 \\
; .9, .1, .1\end{array}\right)$ & $\left(\begin{array}{c}0.7,0.8,0.9,1.0 \\
; .9, .1, .1)\end{array}\right)$ \\
\hline GP & $\left(\begin{array}{c}1.0,1.0,1.0,1.0 \\
; 1.0,0,0\end{array}\right)$ & $\left(\begin{array}{c}0.1,0.1,0.1,0.1 \\
; .5, .3, .3\end{array}\right)$ & $(0.5,0.5,0.5,0.5)$ & $\left(\begin{array}{c}0.8,0.9,1.0,1.0 \\
; .9, .1, .1\end{array}\right)$ & $\left(\begin{array}{c}0.3,0.4,0.5,0.6 \\
; .7, .1, .1\end{array}\right)$ & $\left(\begin{array}{c}1.0,1.0,1.0,1.0 \\
; 1.0,0,0\end{array}\right)$ & $\left(\begin{array}{c}0.5,0.6,0.7,0.8 \\
; .7, .3, .3\end{array}\right)$ & $\left(\begin{array}{c}0.4,0.5,0.6,0.7 \\
; .8,0, .1\end{array}\right)$ \\
\hline CM & $\left(\begin{array}{c}0.3,0.4,0.5,0.6 \\
; .7, .1, .1\end{array}\right)$ & $\left(\begin{array}{c}0.5,0.6,0.7,0.8 \\
; .7, .3, .3\end{array}\right)$ & $\left(\begin{array}{c}0.3,0.4,0.5,0.6 \\
; .7, .1, .1\end{array}\right)$ & $(0.5,0.5,0.5,0.5)$ & $\left(\begin{array}{c}0.7,0.8,0.9,1.0 \\
; .9, .1, .1)\end{array}\right)$ & $\left(\begin{array}{c}0.3,0.4,0.5,0.6 \\
; .7, .1, .1\end{array}\right)$ & $\left(\begin{array}{c}0.6,0.7,0.8,0.9 \\
; .8,2, .3\end{array}\right)$ & $\left(\begin{array}{c}0.6,0.7,0.8,0.9 \\
; .8,2 . .3\end{array}\right)$ \\
\hline SEC & $\left(\begin{array}{c}(0.7,0.8,0.9,1.0 \\
; .9, .1, .1)\end{array}\right)$ & $\left(\begin{array}{c}0.6,0.7,0.8,0.9 \\
; .8, .2, .3\end{array}\right)$ & $\left(\begin{array}{c}1.0,1.0,1.0,1.0 \\
; 1.0,0,0\end{array}\right)$ & $\left(\begin{array}{c}0.1,0.1,0.1,0.1 \\
; .5, .3, .3\end{array}\right)$ & $(0.5,0.5,0.5,0.5)$ & $\left(\begin{array}{c}0.7,0.8,0.9,1.0 \\
; .9, .1, .1)\end{array}\right)$ & $\left(\begin{array}{c}0.4,0.5,0.6,0.7 \\
; .8,0, .1\end{array}\right)$ & $\left(\begin{array}{c}0.3,0.4,0.5,0.6 \\
; .7, .1, .1\end{array}\right)$ \\
\hline CEC & $\left(\begin{array}{c}0.4,0.5,0.6,0.7 \\
; .8,0, .1\end{array}\right)$ & $\left(\begin{array}{c}0.4,0.5,0.6,0.7 \\
; .8,0, .1\end{array}\right)$ & $\left(\begin{array}{c}0.3,0.4,0.5,0.6 \\
; .7, .1, .1\end{array}\right)$ & $\left(\begin{array}{c}0.5,0.6,0.7,0.8 \\
; .7, .3, .3\end{array}\right)$ & $\left(\begin{array}{c}0.4,0.5,0.6,0.7 \\
; .8,0, .1\end{array}\right)$ & $(0.5,0.5,0.5,0.5)$ & $\left(\begin{array}{c}0.7,0.8,0.9,1.0 \\
; .9, .1, .1)\end{array}\right)$ & $\left(\begin{array}{c}0.5,0.6,0.7,0.8 \\
; .7, .3, .3\end{array}\right)$ \\
\hline ENP & $\left(\begin{array}{c}0.6,0.7,0.8,0.9 \\
; .8, .2, .3\end{array}\right)$ & $\left(\begin{array}{c}(0.7,0.8,0.9,1.0 \\
; .9,1, .1)\end{array}\right)$ & $\left(\begin{array}{c}(0.7,0.8,0.9,1.0 \\
; .9, .1, .1)\end{array}\right)$ & $\left(\begin{array}{c}0.6,0.7,0.8,0.9 \\
; .8,2, .3\end{array}\right)$ & $\left(\begin{array}{c}0.3,0.4,0.5,0.6 \\
; .7, .1, .1\end{array}\right)$ & $\left(\begin{array}{c}0.4,0.5,0.6,0.7 \\
; .8,0, .1\end{array}\right)$ & $(0.5,0.5,0.5,0.5)$ & $\left(\begin{array}{c}0.8,0.9,1.0,1.0 \\
; .9, .1, .1\end{array}\right)$ \\
\hline ECP & $\left(\begin{array}{c}0.5,0.6,0.7,0.8 \\
; .7, .3, .3\end{array}\right)$ & $\left(\begin{array}{c}0.3,0.4,0.5,0.6 \\
; .7, .1, .1\end{array}\right)$ & $\left(\begin{array}{c}0.4,0.5,0.6,0.7 \\
; .8,0, .1\end{array}\right)$ & $\left(\begin{array}{c}0.4,0.5,0.6,0.7 \\
; .8,0, .1\end{array}\right)$ & $\left(\begin{array}{c}0.7,0.8,0.9,1.0 \\
; .9, .1, .1)\end{array}\right)$ & $\left(\begin{array}{c}0.6,0.7,0.8,0.9 \\
; .8, .2, .3\end{array}\right)$ & $\left(\begin{array}{c}0.3,0.4,0.5,0.6 \\
; .7, .1, .1\end{array}\right)$ & $(0.5,0.5,0.5,0.5)$ \\
\hline
\end{tabular}


Table 16 The crisp values of relation matrix

\begin{tabular}{lllllllll}
\hline Practice name & RL & GD & GP & CM & SEC & CEC & ENP & ECP \\
\hline RL & 0.500 & 0.624 & 0.048 & 0.341 & 0.048 & 0.193 & 0.341 & 0.048 \\
GD & 0.193 & 0.500 & 0.371 & 0.341 & 0.574 & 0.193 & 0.624 & 0.574 \\
GP & 0.750 & 0.048 & 0.500 & 0.624 & 0.281 & 0.750 & 0.341 & 0.371 \\
CM & 0.281 & 0.341 & 0.281 & 0.500 & 0.574 & 0.281 & 0.431 & 0.431 \\
SEC & 0.574 & 0.431 & 0.750 & 0.048 & 0.500 & 0.574 & 0.371 & 0.281 \\
CEC & 0.371 & 0.371 & 0.281 & 0.341 & 0.371 & 0.500 & 0.574 & 0.341 \\
ENP & 0.341 & 0.371 & 0.574 & 0.431 & 0.281 & 0.371 & 0.500 & 0.624 \\
ECP & 0.341 & 0.281 & 0.371 & 0.371 & 0.574 & 0.431 & 0.281 & 0.500 \\
\hline
\end{tabular}

Table 17 The row average of matrix

\begin{tabular}{lc}
\hline Practice name & Avg. \\
\hline RL & 0.27 \\
GD & 0.41 \\
GP & 0.45 \\
CM & 0.39 \\
SEC & 0.43 \\
CEC & 0.39 \\
ENP & 0.43 \\
ECP & 0.39 \\
\hline
\end{tabular}

Table 18 The result of comparing average

\begin{tabular}{lllll}
\hline $\begin{array}{l}\text { Practice } \\
\text { name }\end{array}$ & $\begin{array}{l}\text { Expert } \\
\text { 1 Avg. }\end{array}$ & $\begin{array}{l}\text { Expert } \\
\text { 2 Avg. }\end{array}$ & {$[\tilde{A} \mathrm{U}, \tilde{A} \mathrm{~L}]$} & $(\tilde{L}, a, b, \tilde{r})$ \\
\hline RL & 0.35 & 0.27 & {$[0.27,0.35]$} & $(0.27,0.28,0.30,0.35)$ \\
GD & 0.42 & 0.41 & {$[0.41,0.42]$} & $(0.41,0.411,0.412,0.42)$ \\
GP & 0.46 & 0.45 & {$[0.45,0.46]$} & $(0.45,0.451,0.452,0.46)$ \\
CM & 0.39 & 0.40 & {$[0.39,0.40]$} & $(0.39,0.391,0.392,0.40)$ \\
SEC & 0.44 & 0.43 & {$[0.43,0.44]$} & $(0.43,0.431,0.432,0.44)$ \\
CEC & 0.38 & 0.39 & {$[0.38,0.39]$} & $(0.38,381,0.382,0.39)$ \\
ENP & 0.47 & 0.43 & {$[0.43,0.47]$} & $(0.43,0.44,0.46,0.47)$ \\
ECP & 0.40 & 0.39 & {$[0.39,0.40]$} & $(0.39,0.391,0.392,0.40)$ \\
\hline
\end{tabular}

Table 19 The result of robust ranking

\begin{tabular}{lll}
\hline Practice name & $\mathrm{R}(\tilde{A})$ & $\begin{array}{l}\text { Order of operators } \\
\text { using robust ranking }\end{array}$ \\
\hline RL & 0.30 & RL \\
GD & 0.41 & CEC \\
GP & 0.45 & CM \\
CM & 0.39 & GD \\
SEC & 0.43 & ECP \\
CEC & 0.38 & SEC \\
ENP & 0.44 & ENP \\
ECP & 0.41 & GP \\
\hline
\end{tabular}

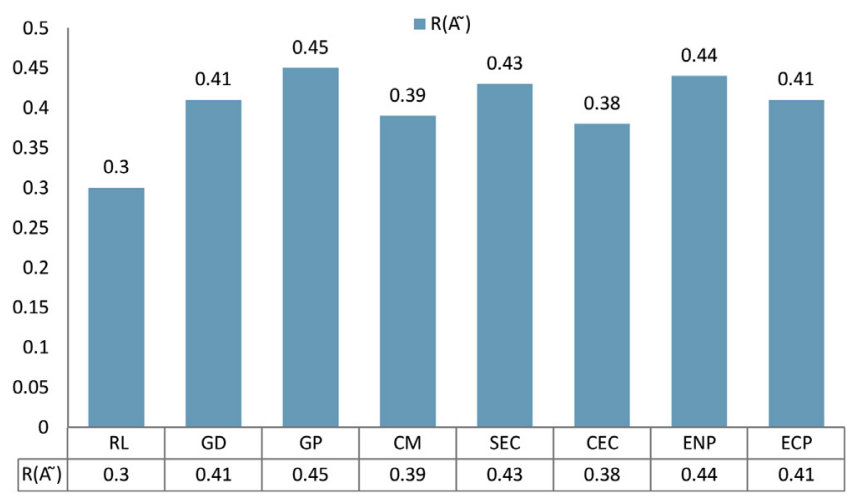

Fig. 8. Ranking of the result.

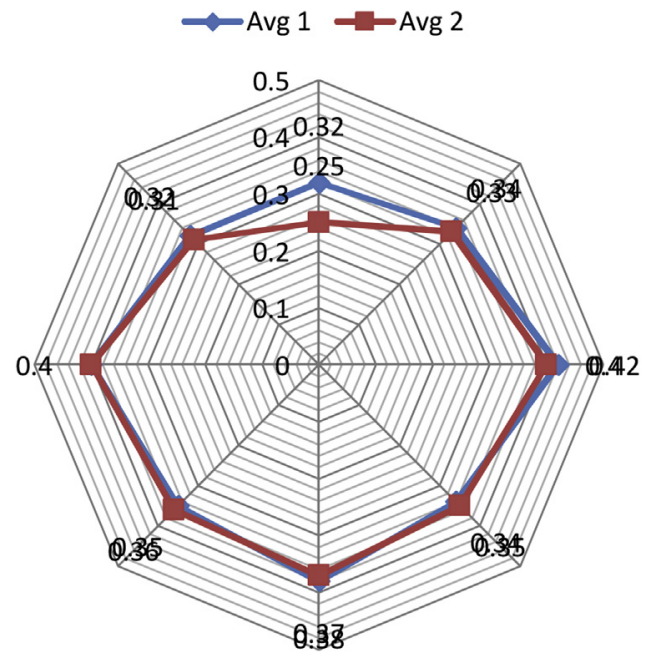

Fig. 9. The result of comparing average for Firm A before using our recommendation.

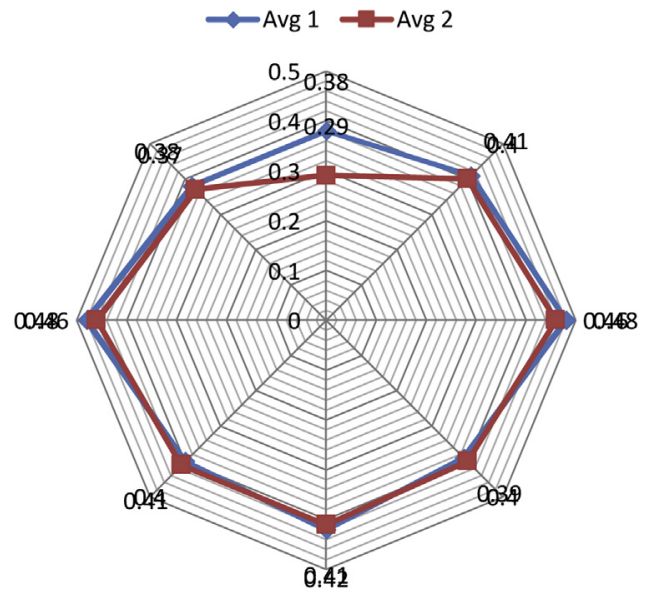

Fig. 10. The result of comparing average for Firm A after using our recommendation.

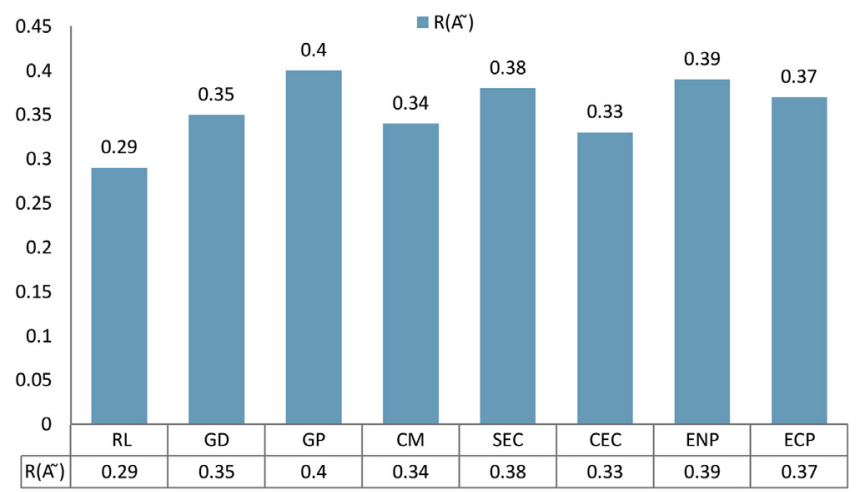

Fig. 11. Ranking of the results before adopting our recommendation.

improvements and allow direct comparisons before and after adopting our proposal.

Figs. 9 and 10 show scores before and after adopting our proposal for six months. There are overall improvements between $10 \%$ and $17 \%$. This is important for green suppliers to illustrate the level of improvement and our proposal as a valid recommendation. Similarly, Figs. 11 and 12 show the scores before and after adopting 


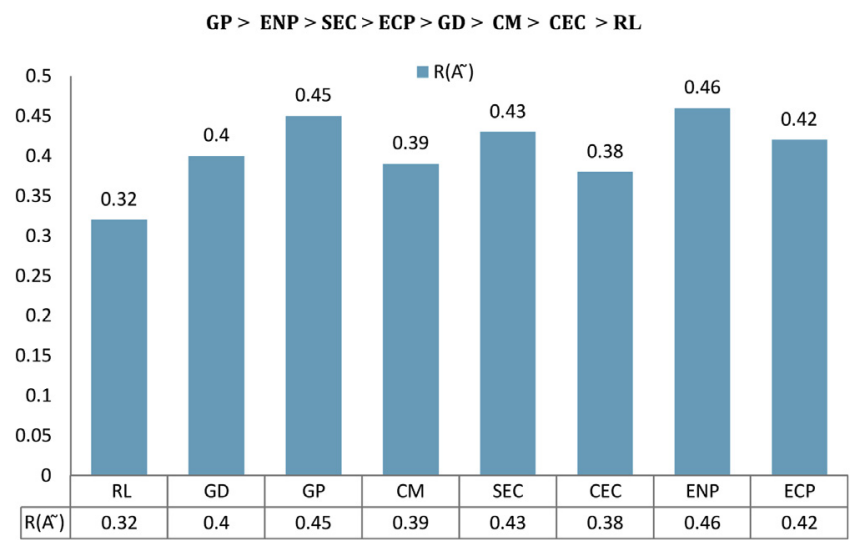

Fig. 12. Ranking of the results before adopting our recommendation.

our proposal for six months. All the scores are higher in Fig. 12 in all aspects. There is an improvement between $8 \%$ and $13 \%$. We have the same result, GP $>\mathrm{ENP}>\mathrm{SEC}>\mathrm{ECP}>\mathrm{GD}>\mathrm{CM}>\mathrm{CEC}>\mathrm{RL}$, like the first case study.

Results in Figs. 7 and 12 show that Green Purchasing (GP) scored the highest. This is because all suppliers require the purchasing activities as their main focus. This allows them to sell their products and services to existing and new customers. In this process, it also makes direct influences on manufacturing. The more sale orders are made, the more products are then manufactured. Additionally, transportation and supply chain activities are also significantly raised due to the increased GP activities. This case study can demonstrate that our proposal can help green supply chain.

\section{Discussion}

Many organizations consider a significant strategic topic integrating environmental measures into SCM. GSCM is important for organizations and enterprises to enhance competitive advantages, market share and profitability. Nowadays, organizations and companies should implement GSCM practices into their business operations due to increased community concerns and strict regulations. Some research outputs indicate how GSCM practices can improve an organization's approach for environments.

Organizations can reach balanced economic and environmental performance through analysis of interrelated problems. Organizations and enterprises should consider the importance of GSCM practices and how it could affect their economic and environmental performance in business operations. Case studies can provide suitable methodologies to validate our approach. Therefore, we presented two case studies with different sectors and different countries to show that our work can be adopted with consistency. The first case study includes the implementation in a petroleum manufacturing company, and the second case study involve with manufacturing firm for automated machineries. Our steps to obtain results were discussed and different aspects of GSCM were demonstrated. Results and analysis could call for attention to reverse logistics, supplier environmental collaboration, and carbon management.

Our research contributions include as follows. First, we can demonstrate a logical, structured and step-by-step neutrosophic research approach to determine the selection of the green supply chain. Second, the use of case studies can be further support the validity of our research contributions, since we can blend theories and real-life examples well. We have analyzed issues in Egypt and
China, and have demonstrated our recommendations and practical solutions, particularly for GSCM cases and practices.

Our research is not free from limitations, since we only employed a limited number of experts. The first recommended approach could include using more experts to validate, so that other researchers could repeat the proposed method using multiple experts. The second recommendation is to develop algorithms to help predict the future trends and perspectives. For example, the use of Organizational Sustainability Modeling (OSM) and Reuse Strategic Decision Pattern Framework can be used to predict the future trends, business performance and risk $[36,37]$.

\section{Conclusion and future work}

GSCM practices and performances could be developed using neutrosophic set and robust ranking technique. In this paper, we proposed an approach for GSCM to develop robust ranking technique by implementing neutrosophic set to avoid unclear, vague and inexact opinions. An effective GSCM practice should develop firstly "reverse logistics", followed by "supplier environmental collaboration", and finally "carbon management". By following our steps carefully, the organization could improve performance through establishing good GSCM practices and performances. Two case studies were illustrated to show our approach can be validated in different context. The major contribution of both case studies consists in integrating the neutrosophic set and the robust ranking technique, in order to determine the best practices for GSCM implementation in petroleum industry.

Our conclusion was that GSCM practices could reduce waste, cost declines, offer economic advantages and better resources use. Therefore, GSCM practices could play an important role in the development of organizations toward economic and environmental benefits. Applying the neutrosophic set in this research helped us to handle vague data, imprecise knowledge, incomplete information and linguistic imprecision. Support of two case studies could consolidate the validity of our approach and demonstrated our case could be adopted. We could also compare the extents of improvement between before and after adopting our recommendations.

Future directions include the use of algorithms to predict the future trends. This can blend theories and simulations better and quicker. Similarly, the use of analytics can be developed together with neutrosophic research to make it an intelligent service. For the future work, we plan to blend our current work with algorithms to simulate predictive modeling and user behavior analysis. Predicting the trends and business performance can be essential for all the stakeholders and decision-makers.

\section{References}

[1] S. Luthra, S.K. Mangla, R. Shankar, C.P. Garg, S. Jakhar, Modelling critical success factors for sustainability initiatives in supply chains in Indian context using Grey-DEMATEL, Prod. Plan. Control 29 (9) (2018) 705-728, doi:http://dx.doi. org/10.1080/09537287.2018.1448126.

[2] K.-H. Lee, Integrating carbon footprint into supply chain management: the case of Hyundai Motor Company (HMC) in the automobile industry, J. Clean. Prod. 19 (11) (2011) 1216-1223, doi:http://dx.doi.org/10.1016/j. jclepro.2011.03.010.

[3] A.B.L.de S. Jabbour, Understanding the genesis of green supply chain management: lessons from leading Brazilian companies, J. Clean. Prod. 87 (2015) 385-390, doi:http://dx.doi.org/10.1016/j.jclepro.2014.09.034.

[4] A. Rajeev, R.K. Pati, S.S. Padhi, K. Govindan, Evolution of sustainability in supply chain management: a literature review, J. Clean. Prod. 162 (2017) 299-314, doi: http://dx.doi.org/10.1016/j.jclepro.2017.05.026.

[5] P. Rao, D. Holt, Do green supply chains lead to competitiveness and economic performance? Int. J. Oper. Prod. Manag. 25 (9) (2005) 898-916, doi:http://dx. doi.org/10.1108/01443570510613956. 
[6] K. Singjai, L. Winata, T.-F. Kummer, Green initiatives and their competitive advantage for the hotel industry in developing countries, Int. J. Hosp. Manag. 75 (2018) 131-143, doi:http://dx.doi.org/10.1016/j.ijhm.2018.03.007.

[7] M. Abdel-Basset, G. Manogaran, A. Gamal, F. Smarandache, A hybrid approach of neutrosophic sets and DEMATEL method for developing supplier selection criteria, Design Automation for Embedded Systems, (2018), doi:http://dx.doi. org/10.1007/s10617-018-9203-6.

[8] M. Abdel-Basset, M. Mohamed, The role of single valued neutrosophic sets and rough sets in smart city: imperfect and incomplete information systems, Measurement 124 (2018) 47-55, doi:http://dx.doi.org/10.1016/j. measurement.2018.04.001.

[9] J. Ye, Single valued neutrosophic cross-entropy for multicriteria decision making problems, Appl. Math. Model. 38 (3) (2014) 1170-1175, doi:http://dx. doi.org/10.1016/j.apm.2013.07.020.

[10] M.A. Basset, M. Mohamed, A.K. Sangaiah, V. Jain, An integrated neutrosophic AHP and SWOT method for strategic planning methodology selection, Benchmark. Int. J. (2018), doi:http://dx.doi.org/ 10.1108/bij-08-2017-0232.

[11] M. Abdel-Basset, G. Manogaran, M. Mohamed, N. Chilamkurti, Three-way decisions based on neutrosophic sets and AHP-QFD framework for supplier selection problem, Fut. Gen. Comput. Syst. 89 (2018) 19-30, doi:http://dx.doi. org/10.1016/j.future.2018.06.024.

[12] M. Abdel-Basset, M. Mohamed, A.-N. Hussien, A.K. Sangaiah, A novel group decision-making model based on triangular neutrosophic numbers, Soft Comput. (2017), doi:http://dx.doi.org/10.1007/s00500-017-2758-5.

[13] R. Liang, J. Wang, H. Zhang, A multi-criteria decision-making method based on single-valued trapezoidal neutrosophic preference relations with complete weight information, Neural Computing and Applications, (2017), doi:http://dx. doi.org/10.1007/s00521-017-2925-8.

[14] W. Liu, et al., A multi-objective perspective on robust ranking and selection, Simulation Conference (WSC), 2017 Winter, IEEE, 2017.

[15] H. Garg, A robust ranking method for intuitionistic multiplicative sets under crisp, interval environments and its applications, IEEE Trans. Emerg. Top. Comput. Intell. 1 (5) (2017) 366-374, doi:http://dx.doi.org/10.1109/ tetci.2017.2739129.

[16] A. Bhaumik, S.K. Roy, D.-F. Li, Analysis of triangular intuitionistic fuzzy matrix games using robust ranking, J. Intell. Fuzzy Syst. 33 (1) (2017) 327-336, doi: http://dx.doi.org/10.3233/jifs-161631.

[17] S. Gao, H. Xiao, E. Zhou, W. Chen, Robust ranking and selection with optimal computing budget allocation, Automatica 81 (2017) 30-36, doi:http://dx.doi. org/10.1016/j.automatica.2017.03.019.

[18] K. Petljak, K. Zulauf, I. Štulec, S. Seuring, R. Wagner, Green supply chain management in food retailing: survey-based evidence in Croatia, Supply Chain Manag. Int. J. 23 (1) (2018) 1-15, doi:http://dx.doi.org/10.1108/scm-04-20170133.

[19] U. Mumtaz, Y. Ali, A. Petrillo, A linear regression approach to evaluate the green supply chain management impact on industrial organizational performance, Sci. Total Environ. 624 (2018) 162-169, doi:http://dx.doi.org/10.1016/j. scitotenv.2017.12.089.

[20] J. Kaur, R. Sidhu, A. Awasthi, S. Chauhan, S. Goyal, A DEMATEL based approach for investigating barriers in green supply chain management in Canadian manufacturing firms, Int. J. Prod. Res. 56 (1-2) (2017) 312-332, doi:http://dx. doi.org/10.1080/00207543.2017.1395522.

[21] K. Samir, Srivastava, Green supply-chain management: a state-of-the-art literature review, Int. J. Manag. Rev. 9 (1) (2007) 53-80, doi:http://dx.doi.org/ 10.1111/j.1468-2370.2007.00202.x.

[22] R. Geng, S.A. Mansouri, E. Aktas, The relationship between green supply chain management and performance: a meta-analysis of empirical evidences in Asian emerging economies, Int. J. Prod. Econ. 183 (2017) 245-258, doi:http:// dx.doi.org/10.1016/j.ijpe.2016.10.008.

[23] R. Zhao, Y. Liu, N. Zhang, T. Huang, An optimization model for green supply chain management by using a big data analytic approach, J. Clean. Prod. 142 (2017) 1085-1097, doi:http://dx.doi.org/10.1016/j.jclepro.2016.03.006.

[24] Q. Zhu, Y. Qu, Y. Geng, T. Fujita, A comparison of regulatory awareness and green supply chain management practices among Chinese and Japanese manufacturers, Bus. Strat. Environ. 26 (1) (2015) 18-30, doi:http://dx.doi.org/ 10.1002 /bse. 1888 .

[25] Q. Zhu, J. Sarkis, K. Lai, Confirmation of a measurement model for green supply chain management practices implementation, Int. J. Prod. Econ. 111 (2) (2008) 261-273, doi:http://dx.doi.org/10.1016/j.ijpe.2006.11.029.

[26] K.W. Green, D. Whitten, R.A. Inman, The impact of logistics performance on organizational performance in a supply chain context, Supply Chain Manag.
Int. J. 13 (4) (2008) 317-327, doi:http://dx.doi.org/10.1108 13598540810882206

[27] J.D. McGhee, M.C. Sleumer, M. Bilenky, K. Wong, S.J. McKay, B. Goszczynski, H. Tian, N.D. Krich, J. Khattra, R.A. Holt, D.L. Baillie, Y. Kohara, M.A. Marra, S.J.M. Jones, D.G. Moerman, A.G. Robertson, The ELT-2 GATA-factor and the global regulation of transcription in the C. elegans intestine, Dev. Biol. 302 (2) (2007) 627-645, doi:http://dx.doi.org/10.1016/j.ydbio.2006.10.024.

[28] S. Hajmohammad, S. Vachon, R.D. Klassen, I. Gavronski, Reprint of Lean management and supply management: their role in green practices and performance, J. Clean. Prod. 56 (2013) 86-93, doi:http://dx.doi.org/10.1016/j. jclepro.2013.06.038.

[29] F. Smarandache, Neutrosophy. Neutrosophic Probability, Set, and Logic ProQuest Information \& Learning, Ann Arbor, MI, USA, 1998105 pp. http:// fs.unm.edu/eBook-Neutrosophics6.pdf (online edition).

[30] I.M. Hezam, M. Abdel-Baset, F. Smarandache, Taylor series approximation to solve neutrosophic multiobjective programming problem, Neutrosophic Sets Syst. 10 (2015) 39-46.

[31] N. El-Hefenawy, M.A. Metwally, Z.M. Ahmed, I.M. El-Henawy, A review on the applications of neutrosophic sets, J. Comput. Theor. Nanosci.13 (1) (2016) 936944.

[32] T.L. Saaty, L.G. Vargas, Decision Making with the Analytic Network Process Economic, Political, Social and Technological Applications with Benefits, Opportunities, Costs and Risks, Springer Science, 2006 ISBN 978-0-38733987-0.

[33] M. Abdel-Baset, I.M. Hezam, F. Smarandache, Neutrosophic goal programming Neutrosophic Sets Syst. 11 (2016) 112-118.

[34] I.M. Mahdi, M.J. Riley, S.M. Fereig, A.P. Alex, A multi-criteria approach to contractor selection, Eng. Constr. Archit. Manag. 9 (1) (2002) 29-37.

[35] M. Abdel-Basset, et al., Neutrosophic AHP-Delphi Group decision making model based on trapezoidal neutrosophic numbers, J. Ambient Intell. Humaniz. Comput. (2017) 1-17.

[36] V. Chang, Presenting cloud business performance for manufacturing organizations, Inf. Syst. Front. (2017) 1-17, doi:http://dx.doi.org/10.1007/ s10796-017-9798-3.

[37] V. Chang, M. Abdel-Basset, M. Ramachandran, Towards a reuse strategic decision pattern framework - from theories to practices, Inf. Syst. Front. (2018) 1-18, doi:http://dx.doi.org/10.1007/s10796-018-9853-8.

[38] C. Voss, Case research in operations management, Researching Operations Management, Routledge, 2010, pp. 176-209.

[39] A. Halinen, J.Å. Törnroos, Using case methods in the study of contemporary business networks, J. Bus. Res. 58 (9) (2005) 1285-1297.

M. Abdel-Baset obtained the PhD degree on Decision Support -Operations Research at Menoufia University, Faculty of Computers and Informatics, Egypt. His major fields include Artificial Intelligence, Data Mining, Soft Computing, Fuzzy Computing and Decision support systems. He is also an/a Editor/reviewer in different international journals and conferences. He currently serves as an Associate Professor at Zagazig University, Faculty of Computers and Informatics, Department of Decision Support, Egypt. He has more than 100 publications at various international conferences proceedings, workshops, scientific journals and book chapters.

Victor Chang Prof. Victor Chang is an Associate Professor (Reader), Director of PhD and Director of MRes at International Business School Suzhou (IBSS), Xi'an JiaotongLiverpool University, Suzhou, China, after working as a Senior Lecturer at Leeds Beckett University, UK, for 3.5 years.. He is widely regarded as a leading expert on Big Data/Cloud/IoT/security. He is a visiting scholar/PhD examiner at several universities, an Editor-in-Chief of IJOCI \& OJBD journals, Editor of FGCS, Associate Editor of TII, founding chair of two international workshops and founding Conference Chair of IoTBDS http://www.iotbd.org and COMPLEXIS http://www. complexis.org since Year 2016. He was involved in different projects worth more than $£ 12.5$ million in Europe and Asia. He has published 3 books as sole authors and the editor of 2 books on Cloud Computing and related technologies.

Abduallah Gamal Received his B.Sc. from Zagazig University, Faculty of Computers and Informatics, Department of Operations Research, Egypt. His area of interest includes computation intelligence, Optimization, Swarm Intelligence, Evolutionary Algorithms, and neutrosophic sets and logic. 